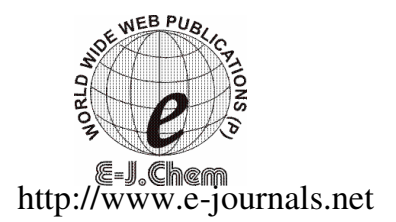

\title{
Synthesis, Spectroscopic Studies and Antifungal Activity of 2-[(4(3-Chlorophenyl) piperazine-1-yl)methyl]-3-[8-hydroxy quinolin-5-yl]- 3(H)-quinazolin-4-one Ligand and its Chelates
}

\author{
R. T. VASHI ${ }^{*}$, C. D. SHELAT and HIMANSHU PATEL \\ Department of Chemistry \\ Navyug Science College, Surat-395009, India \\ vashirajendra@yahoo.co.in
}

Received 6 March 2010; Accepted 22 May 2010

\begin{abstract}
The novel ligand $\mathrm{HL}_{6}$ was synthesized using anthranilic acid and it was undergo the chelating reaction with $\mathrm{Cu}(\mathrm{II}), \mathrm{Ni}(\mathrm{II}), \mathrm{Co}(\mathrm{II}), \mathrm{Mn}(\mathrm{II})$ and $\mathrm{Zn}$ (II) to prepare transition metal chelates. These chelates were characterized by physicochemical methods such as elemental analysis, conductometric studies, magnetic susceptibility, FT-IR, NMR and electronic spectra. The stoichiometry of the complexes has been found to be 1: 2 (Metal: ligand). An octahedral geometry around $\mathrm{Co}(\mathrm{II}), \mathrm{Ni}(\mathrm{II})$ and $\mathrm{Mn}(\mathrm{II})$, distorted octahedral geometry around $\mathrm{Cu}$ (II) and tetrahedral geometry around $\mathrm{Zn}$ (II) have been proposed. The antifungal activity of ligand and its metal chelates were conducted against various fungi.
\end{abstract}

Keywords: 8-Hydroxy quinoline ligand, Complexes, NMR spectral studies, Antifungal activity

\section{Introduction}

8-Hydroxyquinoline or 8-quinolinol is well known as an analytical reagent ${ }^{1}$. The heterocyclic nitrogen compounds especially quinazolinone derivatives play a vital role in many biological processes and as synthetic drugs ${ }^{2}$. Quinazolin-4-one derivative possesses biological activities such as antifungal ${ }^{3,4}$. The 8-hydroxyquinoline and quinazolin-4-one molecules into one molecule have not received any attention in spite of well-defined applications of both the molecules. Hence it was thought to explore the study of qunazolin4-one 8-hydroxyquinoline merged molecules as ligand $\mathrm{HL}_{6}$ with their complexes with $\mathrm{Cu}(\mathrm{II}), \mathrm{Ni}(\mathrm{II}), \mathrm{Co}(\mathrm{II}), \mathrm{Mn}(\mathrm{II})$ and $\mathrm{Zn}(\mathrm{II})$ metal ion. Antimicrobial activities of the ligand and chelates have also been studied. 
General structure of formation of chelates is shown in Scheme1:

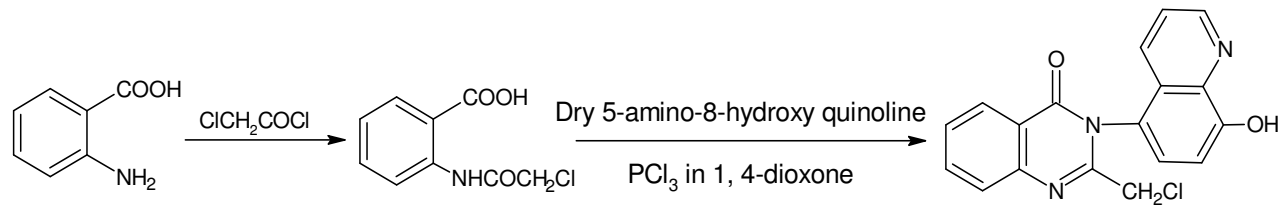

Anthranilic acid

$\mathrm{N}$-chloroacetyl anthranilic acid

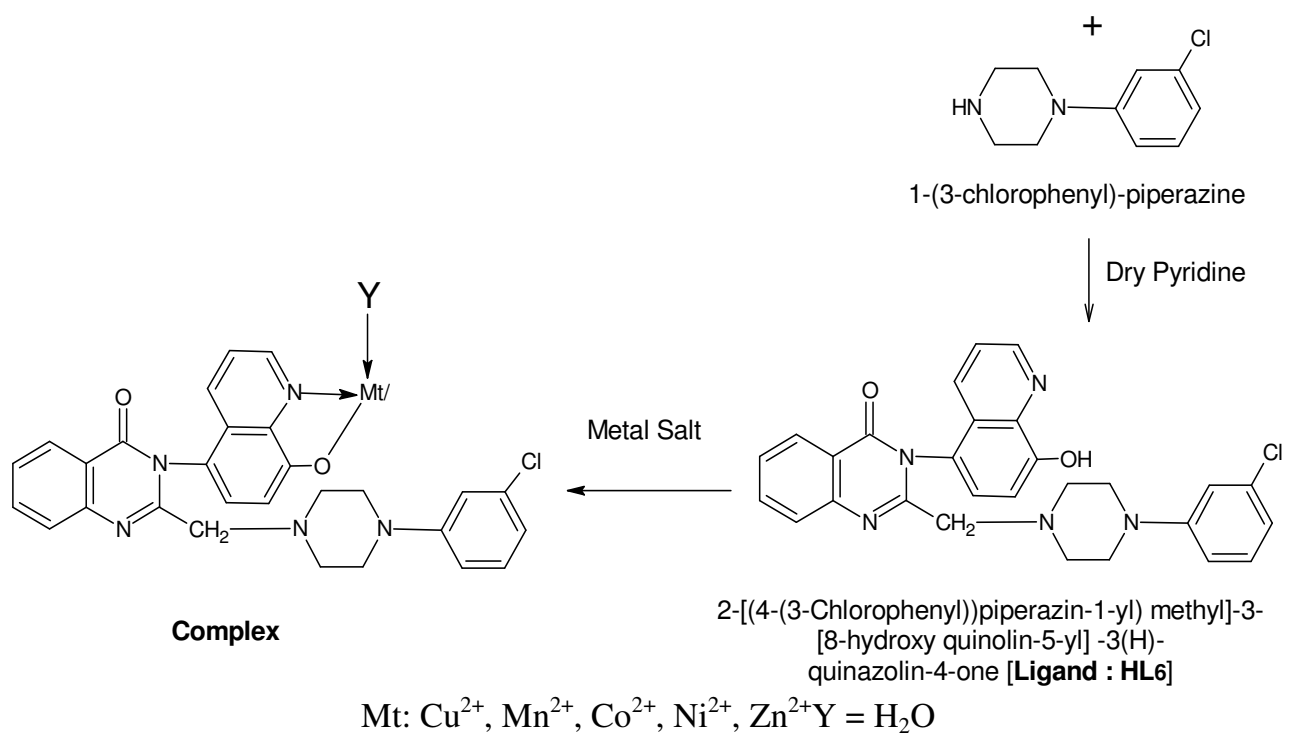

\section{Experimental}

\section{Scheme 1}

All the chemicals used were of pure grade (Merck and B.D.H). Double distilled water was used throughout the experiment. The melting points of all complexes were determined by open capillary method and were uncorrected.

\section{Synthesis of ligand $\mathrm{HL}_{6}$}

The anthranilic acid was converted into $N$-chloroacetyl anthranilic acid by means of chloroacetyl chloride then it refluxed with 5-amino-8-hydroxy quinolin and phosphorous trichloride in dry 1, 4-dioxone under anhydrous condition for $4 \mathrm{~h}$. The reaction mixture was allowed to cool and phosphorous trichloride was decomposed by titrating with cold water. Then, 1, 4-dioxone was distilled off to get the product, 2Chloromethyl -3-(8-hydroxy quinolin-5-yl)-3(H)-quinazolin-4-one. It was filtered and washed with small portion of sodium bicarbonate solution $(10 \%)$ after then extensively with cold water. The mixture of 2-chloromethyl -3-(8-hydroxy quinolin-5-yl)-3(H)quinazolin-4-one and 1-(-3-chlorophenyl)-piperazine in dry pyridine was refluxed for $12 \mathrm{~h}$. Pyridine was distilled off as much as possible and the residue was poured into little crushed ice with stirring. The product, $\mathrm{HL}_{6}$ was separated out, filtered and washed with water and finally with ethanol. The air dried product was quantitative. Melting point for $\mathrm{HL}_{6}$ was $>230{ }^{\circ} \mathrm{C}$. 


\section{Synthesis of chelates}

A dried ligand sample $\mathrm{HL}_{6}(0.01 \mathrm{M})$ was stirred in $85 \%(\mathrm{v} / \mathrm{v})$ formic acid and then it was diluted by water until complete dissolution. The resultant solution was designated as reagent solution. This solution was used for preparation of chelates with particular ligand with transition metal ions. The formic acid solution of ligand was added drop wise to a solution of $\mathrm{Cu}\left(\mathrm{NO}_{3}\right)_{2} \cdot 6 \mathrm{H}_{2} \mathrm{O}, \mathrm{Ni}\left(\mathrm{NO}_{3}\right)_{2} \cdot 6 \mathrm{H}_{2} \mathrm{O}, \mathrm{Co}\left(\mathrm{NO}_{3}\right)_{2} \cdot 6 \mathrm{H}_{2} \mathrm{O}, \mathrm{MnCl}_{2} \cdot 6 \mathrm{H}_{2} \mathrm{O}, \mathrm{Zn}\left(\mathrm{NO}_{3}\right)_{2} \cdot 6 \mathrm{H}_{2} \mathrm{O}(0.005$ mole) in $100 \mathrm{~mL}$ of water with rapid stirring. The resultant $\mathrm{pH} 4.5$ [for $\mathrm{Cu}$ (II), ] pH 6.0 [for $\mathrm{Ni}(\mathrm{II})$ and $\mathrm{Co}(\mathrm{II})$ ] and $\mathrm{pH} 5.6$ [for $\mathrm{Mn}(\mathrm{II})$ and $\mathrm{Zn}(\mathrm{II})$ ] were maintained by addition of sodium acetate. A dark colored solid precipitated out. It was allowed to settle and digested on water bath at $70{ }^{\circ} \mathrm{C}$ for about $2 \mathrm{~h}$. The solid mass was filtered, washed with 1:1 mixture of waterethanol and finally with acetone then dried. The percentage yield of chelates was in the range of $65-80 \%$. All the chelates were powdered well and dried at $70{ }^{\circ} \mathrm{C}$ over a period of $24 \mathrm{~h}$.

The $\mathrm{C}, \mathrm{H}$ and $\mathrm{N}$ contents of metal chelates were determined on elemental analyzer Thermo Finiggan 1101 Flash EA. The metal contents were estimated using standard methods ${ }^{5}$. The molar conductance of the complexes in DMF $\left(10^{-3} \mathrm{M}\right)$ solutions were measured at room temperature using Systronics model 305 direct reading conductivity bridge. ${ }^{1} \mathrm{H}$ NMR spectra of ligand was recorded on Bruner NMR spectrophotometer. PMR chemical shifts are recorded in $\delta$-value using TMS as an internal standard in $\mathrm{CDCl}_{3} / \mathrm{D}_{6}$-DMSO. The IR spectra $(\mathrm{KBr})$ were recorded in the range $4000-600 \mathrm{~cm}^{-1}$ on a Nicolet -760 spectrophotometer. Electronic spectra of the metal chelates were recorded on a Beckman-DK-2A spectrophotometer using $\mathrm{MgO}$ as reference. Magnetic susceptibility ' $\chi_{\mathrm{m}}$ ' was measured by Gouy's method ${ }^{6}$ at room temperature $(300 \mathrm{~K})$ using $\mathrm{Hg}\left[\mathrm{Co}(\mathrm{CNS})_{4}\right]$ as calibrant ${ }^{7}$ and the effective magnetic moment from relation ${ }^{8}$, $\mu_{\text {eff }}=2.84 \sqrt{\chi_{\mathrm{m}} \mathrm{X} T}$, where $\mathrm{T}$ is the absolute temperature. Diamagnetic corrections were made by using Pascal's constants.

The ligand and its metal chelates were screen at $1000 \mathrm{ppm}$ concentration in vitro for their antifungal activity against five fungi viz. Botrydepladia thiobromine, Nigrospora sp., Rhizopus nigricans, Aspergillus fumigatus and Candida albicans. The antifungal activity of the compounds was measured by plate method ${ }^{9}$. Five days old cultures were suspended in potato dextrose agar (PDA) medium and autoclaved at $1200{ }^{\circ} \mathrm{C}$ for 15 minutes and 15 atmospheric pressure. The percentage inhibition of fungi was calculated after 5 days using the formula given below:

$$
\text { Percentage of inhibition }=100(\mathrm{X}-\mathrm{Y}) / \mathrm{X}
$$

Where $\mathrm{X}=$ area of colony in control plate (without sample) and $\mathrm{Y}=$ area of colony in test plate.

\section{Results and Discussion}

The complexes are microcrystalline colored powders having melting points higher than the ligand. They are stable in air at room temperature. All compounds gave satisfactory elemental analysis, suggesting 1:2 (metal: ligand) stoichiometry. Elemental and molar conductance data are shown in Table 1.The result indicates that they are less polar in DMF.

The molar conductance values found to be $25.69,9.79,8.28,8.22$ and $7.68 \mathrm{ohm}^{-1} \mathrm{~cm}^{2} \mathrm{~mol}^{-1}$ for $\mathrm{Co}(\mathrm{II}), \mathrm{Ni}(\mathrm{II}), \mathrm{Mn}$ (II), $\mathrm{Zn}$ (II) and $\mathrm{Cu}$ (II) respectively. So, the electrical conductivity of these chelates was found in the decreasing order: $\mathrm{Co}>\mathrm{Ni}>\mathrm{Mn}>\mathrm{Zn}>\mathrm{Cu}$. The very low values of chelates indicates that they are non-electrolytic ${ }^{10}$ and monomeric in nature. The low conductance values may be attributed to the large cations ${ }^{11}$. 
Table 1. Analytical and physical data of metal chelates of ligand $\mathrm{HL}_{6}$

\begin{tabular}{|c|c|c|c|c|c|c|c|c|}
\hline \multirow{2}{*}{$\begin{array}{c}\text { Ligand / } \\
\text { Mol. Formula }\end{array}$} & \multirow{2}{*}{$\begin{array}{l}\text { M. W. } \\
\text { g/mole }\end{array}$} & \multirow{2}{*}{$\begin{array}{c}\text { Yield } \\
\%\end{array}$} & \multicolumn{4}{|c|}{$\begin{array}{l}\text { Elemental Analysis, \% } \\
\text { Found, Calc. }\end{array}$} & \multirow{2}{*}{$\begin{array}{r}\text { Observed } \\
\mu_{\text {eff }}, \mathrm{B} . \mathrm{M} \\
\text { (Expected) }\end{array}$} & \multirow{2}{*}{$\begin{array}{c}\Lambda_{\mathrm{M}}, \\
\mathrm{Ohm}^{-1} \mathrm{~cm}^{2} \\
\mathrm{~mol}^{-1} \\
\end{array}$} \\
\hline & & & $\mathrm{C}$ & $\mathrm{H}$ & $\mathrm{N}$ & $\mathrm{M}$ & & \\
\hline $\begin{array}{c}\mathrm{HL}_{6} \\
\mathrm{C}_{28} \mathrm{H}_{24} \mathrm{~N}_{5} \mathrm{O}_{2} \mathrm{Cl}\end{array}$ & 497.50 & 79 & $\begin{array}{c}67.40 \\
(67.53)\end{array}$ & $\begin{array}{c}4.70 \\
(4.82)\end{array}$ & $\begin{array}{c}14.00 \\
(14.07)\end{array}$ & - & - & - \\
\hline $\begin{array}{c}\left(\mathrm{HL}_{6}\right)_{2} \mathrm{Cu}^{2+} \\
\mathrm{C}_{56} \mathrm{H}_{50} \mathrm{~N}_{10} \mathrm{O}_{6} \mathrm{Cu}^{2+} \mathrm{Cl}_{2}\end{array}$ & 1092.54 & 69 & $\begin{array}{c}65.70 \\
(65.78)\end{array}$ & $\begin{array}{c}4.60 \\
(4.69)\end{array}$ & $\begin{array}{l}13.60 \\
(13.70)\end{array}$ & $\begin{array}{c}6.20 \\
(6.22)\end{array}$ & $\begin{array}{c}2.09 \\
(1.7-2.2)\end{array}$ & 7.68 \\
\hline $\begin{array}{c}\left(\mathrm{HL}_{6}\right)_{2} \mathrm{Ni}^{2+} \\
\mathrm{C}_{56} \mathrm{H}_{50} \mathrm{~N}_{10} \mathrm{O}_{6} \mathrm{Ni}^{2+} \mathrm{Cl}_{2}\end{array}$ & 1087.69 & 76 & $\begin{array}{l}65.00 \\
(66.09)\end{array}$ & $\begin{array}{c}4.60 \\
(4.70)\end{array}$ & $\begin{array}{l}13.60 \\
(13.77)\end{array}$ & $\begin{array}{c}5.60 \\
(5.77)\end{array}$ & $\begin{array}{c}3.12 \\
(2.9-3.4)\end{array}$ & 9.79 \\
\hline $\begin{array}{c}\left(\mathrm{HL}_{6}\right)_{2} \mathrm{Co}^{2+} \\
\mathrm{C}_{56} \mathrm{H}_{50} \mathrm{~N}_{10} \mathrm{O}_{6} \mathrm{Co}^{2+} \mathrm{Cl}_{2}\end{array}$ & 1087.90 & 59 & $\begin{array}{c}66.00 \\
(66.08)\end{array}$ & $\begin{array}{c}4.70 \\
(4.72)\end{array}$ & $\begin{array}{l}13.70 \\
(13.76)\end{array}$ & $\begin{array}{c}5.70 \\
(5.79)\end{array}$ & $\begin{array}{c}5.10 \\
(4.4-5.2)\end{array}$ & 25.69 \\
\hline $\begin{array}{c}\left(\mathrm{HL}_{6}\right)_{2} \mathrm{Mn}^{2+} \\
\mathrm{C}_{56} \mathrm{H}_{50} \mathrm{~N}_{10} \mathrm{O}_{6} \mathrm{Mn}^{2+} \mathrm{Cl}_{2}\end{array}$ & 1083.93 & 65 & $\begin{array}{l}66.30 \\
(66.34)\end{array}$ & $\begin{array}{c}4.70 \\
(4.73)\end{array}$ & $\begin{array}{c}13.00 \\
(13.82)\end{array}$ & $\begin{array}{c}5.30 \\
(5.36)\end{array}$ & $\begin{array}{c}5.32 \\
(5.2-6.0)\end{array}$ & 8.28 \\
\hline $\begin{array}{c}\left(\mathrm{HL}_{6}\right)_{2} \mathrm{Zn}^{2+} \\
\mathrm{C}_{56} \mathrm{H}_{50} \mathrm{~N}_{10} \mathrm{O}_{6} \mathrm{Zn}^{2+} \mathrm{Cl}_{2} \\
\end{array}$ & 1094.39 & 72 & $\begin{array}{r}65.60 \\
(65.66) \\
\end{array}$ & $\begin{array}{c}4.60 \\
(4.70) \\
\end{array}$ & $\begin{array}{l}13.60 \\
(13.77)\end{array}$ & $\begin{array}{r}6.10 \\
(6.20) \\
\end{array}$ & 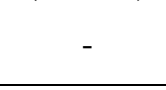 & 8.22 \\
\hline
\end{tabular}

\section{Infrared spectra}

FT-IR spectrum of ligand $\mathrm{HL}_{6}$ show a broad band extended from 3400 to $2600 \mathrm{~cm}^{-1}$ which might be responsible to phenolic group bonded to $\mathrm{N}$ atom of 8 -hydroxy quinoline moiety ${ }^{12}$. The inflextious at 2923, 2852 and $1470 \mathrm{~cm}^{-1}$ are due to aromatic $\mathrm{CH}$ and methylene group of bridge and piperazine ring ${ }^{13}$. The strong band at $1705 \mathrm{~cm}^{-1}$ is attributed to $\mathrm{C}=\mathrm{O}$ of quinazoline 4-one moiety. Several bands appeared between $1500-1600 \mathrm{~cm}^{-1}$ region may arise from aromatic breathing. The IR band at $\sim 1580 \mathrm{~cm}^{-1}$ (C=N of 8-quinolinol system) of $\mathrm{HL}_{6}$ ligand shifted to higher frequency side $\sim 1600$ in the spectra of the metal chelates indicating involvement of nitrogen in the chelate formation ${ }^{12,14}$. Most of bands appeared in the spectra of corresponding ligand are observed at their metal chelates. Only a new band at $1095 \mathrm{~cm}^{-1}$ had appeared in the spectra of metal chelates. This may be assigned to $v$ c-o of C-O-M bond formation. All the complexes show additional bands at $840-830 \mathrm{~cm}^{-1}$ indicating the presence of coordinated water ${ }^{15}$.

\section{NMR spectra}

${ }^{1} \mathrm{H}$ NMR spectra of ligand was depicted in Figure 1, which shows results in $\delta$ ppm as follows: $1.0\left(-\mathrm{CH}_{3}\right), 2.4\left(-\mathrm{CH}_{2}\right), 3.47\left(\mathrm{CH}_{2}\right.$ bridge) 3.44 to 3.52 (triplet $-\mathrm{CH}_{2}$ of piperizine), 3.47 ( $-\mathrm{CH}_{2}$ bridge), 4.82 (singlet of phenolic $-\mathrm{OH}$ ), and 7.1 to 8.84 (multiplet, quinazoline).

\section{Magnetic moment and Electronic spectra}

At room temperature the magnetic moment ' $\mu_{\mathrm{eff}}$ ' values for the Co(II) complex is 5.10 B.M (Table 1) suggest high spin octahedral geometry, which was further supported by the electronic spectral data. The electronic spectra of the Co(II) complex display three absorption bands in the range 8452,19586 and $23215 \mathrm{~cm}^{-1}$, assigned to the transitions ${ }^{4} \mathrm{~T}_{1 \mathrm{~g}}$ $(\mathrm{F}) \rightarrow{ }^{4} \mathrm{~T}_{2 \mathrm{~g}}(\mathrm{~F})\left(\mathrm{v}_{1}\right),{ }^{4} \mathrm{~T}_{1 \mathrm{~g}}(\mathrm{~F}) \rightarrow{ }^{4} \mathrm{~A}_{2 \mathrm{~g}}(\mathrm{~F})\left(\mathrm{v}_{2}\right)$ and ${ }^{4} \mathrm{~T}_{1 \mathrm{~g}}(\mathrm{~F}) \rightarrow{ }^{4} \mathrm{~T}_{1 \mathrm{~g}}(\mathrm{P})\left(\mathrm{v}_{3}\right)$ respectively ${ }^{16}$. The values of transition ratio $v_{2} / v_{1}$ is 2.31 providing further evidences for octahedral geometry for the $\mathrm{Co}$ (II) complexes.

In the $\mathrm{Ni}(\mathrm{II})$ complex, $\mu_{\mathrm{eff}}$ value at room temperature is observed to be $3.12 \mathrm{~B} . \mathrm{M}$. as expected for six coordinated spin free $\mathrm{Ni}(\mathrm{II})$ species. The reflectance spectra of the $\mathrm{Ni}(\mathrm{II})$ complex, exhibit two strong bands at $15009 \mathrm{~cm}^{-1}$ and $24515 \mathrm{~cm}^{-1}$, assignable to ${ }^{3} \mathrm{~A}_{2 \mathrm{~g}}(\mathrm{~F}) \rightarrow{ }^{3} \mathrm{~T}_{1 \mathrm{~g}}$ (F) and ${ }^{3} \mathrm{~A}_{2 \mathrm{~g}}(\mathrm{~F}) \rightarrow{ }^{3} \mathrm{~T}_{1 \mathrm{~g}}(\mathrm{P})$ respectively. The $v_{2} / v_{1}$ ratio for the chelate is 1.63 occurs in the usual range (1.60-1.82) for octahedral $\mathrm{Ni}(\mathrm{II})$ chelates ${ }^{17}$. The spectral bands are well within the range observed for hexacoordinate octahedral complexes reported earlier ${ }^{18}$. 
The $\mathrm{Cu}(\mathrm{II})$ complex exhibit normal magnetic moments (2.09 B.M.) indicating the distorted octahedral geometry, which is in agreement with data reported by several research workers $^{19-20}$. These complex show broad asymmetric bands in the region $14589 \mathrm{~cm}^{-1}$ and at $24856 \mathrm{~cm}^{-1}$ assignable to ${ }^{2} \mathrm{~B}_{1 \mathrm{~g}} \rightarrow{ }^{2} \mathrm{~A}_{1 \mathrm{~g}}$ and charge transfer transition respectively ${ }^{21}$. These results reveal the distorted octahedral geometry for these complexes. The former band may be due to ${ }^{2} \mathrm{E}_{\mathrm{g}} \rightarrow{ }^{2} \mathrm{~T}_{2 \mathrm{~g}}$ accounted due to Jahn Teller effect suggesting thereby a distorted octahedral geometry for these complexes ${ }^{22}$. The values of transition ratio $v_{2} / v_{1}$ is 1.70 . $\mathrm{Zn}(\mathrm{II})$ complexes are diamagnetic as expected for $\mathrm{d}^{10}$ systems and may have tetrahedral geometry ${ }^{23}$.

The electronic spectra of the $\mathrm{Mn}(\mathrm{II})$ exhibited three spin allowed bands in the region 15896, 17954 and $24768 \mathrm{~cm}^{-1}$ assigned to the transitions ${ }^{6} \mathrm{~A}_{1 \mathrm{~g}} \rightarrow{ }^{4} \mathrm{~T}_{1 \mathrm{~g}}\left({ }^{4} \mathrm{G}\right),{ }^{6} \mathrm{~A}_{1 \mathrm{~g}} \rightarrow{ }^{4} \mathrm{~T}_{2 \mathrm{~g}}$ $\left({ }^{4} \mathrm{G}\right)$ and ${ }^{6} \mathrm{~A}_{1 \mathrm{~g}} \rightarrow{ }^{4} \mathrm{E}_{\mathrm{g}},{ }^{4} \mathrm{~T}_{1 \mathrm{~g}}\left({ }^{4} \mathrm{G}\right)$ respectively, indicating octahedral geometry ${ }^{24}$. The observed magnetic moment (5.32 B.M.) of the complexes indicates high spin octahedral environment ${ }^{25}$.

\section{Antifungal activity}

The ligand and chelates were used for their antimicrobial studies by means of fungi, such as Candida albicans, Botrydepladia thibromine, Nigrospora sp, Aspergillus fumigatus and Rhizopur nigricums. Antifungal activity of ligand and complexes shown in Table 2 was in following decreasing order:

$$
\mathrm{Cu}(\mathrm{II})>\mathrm{Ni}(\mathrm{II})>\mathrm{Zn}(\mathrm{II})>\mathrm{Co}(\mathrm{II})>\mathrm{Mn}(\mathrm{II})
$$

Table 2. Antifungal activity of ligand $\mathrm{HL}_{6}$ and its metal chelates

\begin{tabular}{cccccc}
\hline \multirow{2}{*}{ Sample } & \multicolumn{5}{c}{ Zone of inhibition at $1000 \mathrm{pm}, \%$} \\
\cline { 2 - 6 } & $\begin{array}{c}\text { Candida } \\
\text { albicans }\end{array}$ & $\begin{array}{c}\text { Botrydepladia } \\
\text { thibromine }\end{array}$ & $\begin{array}{c}\text { Nigrospora } \\
\text { sp. }\end{array}$ & $\begin{array}{c}\text { Aspergillus } \\
\text { fumigatus }\end{array}$ & $\begin{array}{c}\text { Rhizopur } \\
\text { nigricums }\end{array}$ \\
\hline $\mathrm{HL}_{6}$ & 73 & 56 & 65 & 74 & 72 \\
$\left(\mathrm{HL}_{6}\right)_{2} \mathrm{Cu}^{2+}$ & 88 & 79 & 75 & 89 & 87 \\
$\left(\mathrm{HL}_{6}\right)_{2} \mathrm{Ni}^{2+}$ & 78 & 75 & 79 & 82 & 80 \\
$\left(\mathrm{HL}_{6}\right)_{2} \mathrm{Co}^{2+}$ & 69 & 68 & 59 & 58 & 77 \\
$\left(\mathrm{HL}_{6}\right)_{2} \mathrm{Mn}^{2+}$ & 56 & 56 & 69 & 68 & 67 \\
$\left(\mathrm{HL}_{6}\right)_{2} \mathrm{Zn}^{2+}$ & 77 & 75 & 72 & 72 & 73 \\
\hline
\end{tabular}

The substitutions of phenyl rings by chlorine have much more effect on the fungicidal activity. The results suggest that variation in structure on coordination affects the growth of micro organisms and may result in to inhibitory or reduction in toxicology of metal ions towards some organisms ${ }^{26}$.

\section{Conclusion}

The ligand molecule acts as a hexadentate ligand in all the studied cases of complex. Bonding either among $\mathrm{N}$ (4) depending upon the nature of the metal ions. Octahedral structures for $\mathrm{Ni}(\mathrm{II}), \mathrm{Co}$ (II) and $\mathrm{Mn}$ (II) complexes, tetrahedral polymeric structure for $\mathrm{Zn}(\mathrm{II})$, and distorted octahedral for $\mathrm{Cu}(\mathrm{II})$ complex have been tentatively proposed. Present work will contribute in the field of new antifungal for some plant pathogenic organisms.

\section{Acknowledgment}

The authors are thankful to Department of Chemistry, Navyug Science College, Surat for providing laboratory facilities. 


\section{References}

1. Gribov L A, Sawin S B and Raikhstat M M, Zh Anal Khim., 1980, 35, 1469.

2. $\quad$ Patel N B and Chaudhari R C, J Indian Chem Soc., 2006, 83, 838-841.

3. $\quad$ Robert J A and Russel H E, J Med Chem., 1972, 15, 335.

4. $\quad$ Vashi R T and Patel S B, E-J Chem., 2009, 6 (S1), S445-S451.

5. Vogel A I, Text book of Quantitative Inorganic Analysis. $3^{\text {rd }}$ Ed., ELBS, London, 1978.

6. Lewis J and Wilkins R G, Modern Coordination Chemistry, New Science, New York, 1964.

7. Figgis B N and Lewis J, The Magneto Chemistry of Chelates in Modern Coordination Chemistry, InterScience, New York, 1960.

8. Williams J O, Adv Phys Org Chem., 1979, 16, 159.

9. Barry A L, Antibiotics in Laboratory Medicine, Williams and Wilkins, Baltimore, $3^{\text {rd }}$ Ed., 1996.

10. Geary W J, Coord Chem Rev., 1971, 81.

11. Upadhyay R K, J Indian Chem Soc., 1977, 74, 535-537.

12. Bellamy L J, Infrared spectra of complexes molecules, Chapman and Hall, London, 1957.

13. Silvestein R M, Spectrometric identification of organic compounds, $5^{\text {th }}$ Ed., John Wiley, 1991, 123.

14. Nakamoto K, Infrared and Raman Spectra of Inorganic and Coordination Compounds, $3{ }^{\text {rd }}$ Ed., Wiley- InterScience, New York, 1975.

15. Nakamoto K, Infrared and Raman Spectroscopy of Inorganic and Coordination Compounds, $3^{\text {rd }}$ Ed., Wiley, Inter Science, New York, 1978.

16. Lever A B P, Inorganic Electronic Spectroscopy, Elsevier, New York, 1968.

17. Syamal A and Maurya M R, Synth React Inorg Metal Org Chem., 1986, 16, 39.

18. Singh D P, Shishodia N, Yadav B P and Rana V B, Polyhedron, 1997, 16(13), 2229-2232.

19. Vashi R T, Patel S B and Kadiya H K, Der Pharma Chemca., 2010, 2(1), 109-116.

20. Reddy S N and Agarwal B V, Syn React Inorg Chem., 1987, 17, 10.

21. Chaudhary G L, Prasad S R and Rahman A, J Indian Chem Soc., 1997, 74, 683-685.

22. Satapathy K C , Dash D C , Pradhan G C and Naik A, J Indian Chem Soc., 1989, 66, 292.

23. Yidiz M, Dulger B , Koyuncu S Y K and Yanpici M B, J Indian Chem Soc., 2004, 81, 7.

24. Aswar A S and Bhava N S, J. Indian Chem Soc., 1997, 4, 75.

25. Sahu B K and Mahapatra B K, J Indian Chem Soc., 1979, 56, 825.

26. Patel M M and Patel H R, J Indian Chem Soc., 1996, 73, 313- 317. 


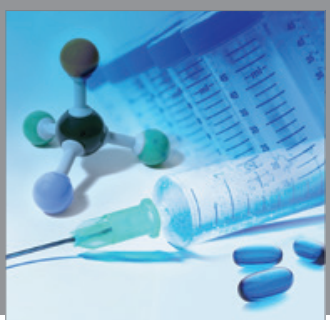

International Journal of

Medicinal Chemistry

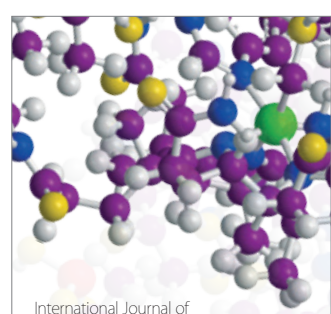

Carbohydrate Chemistry

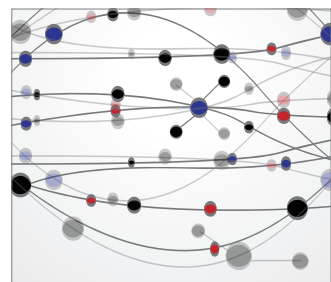

The Scientific World Journal
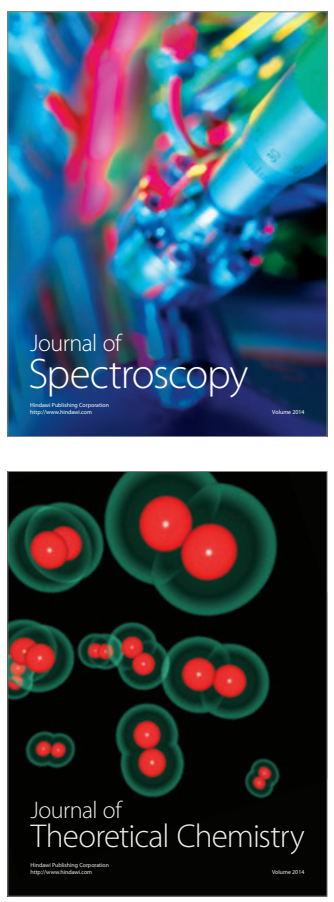
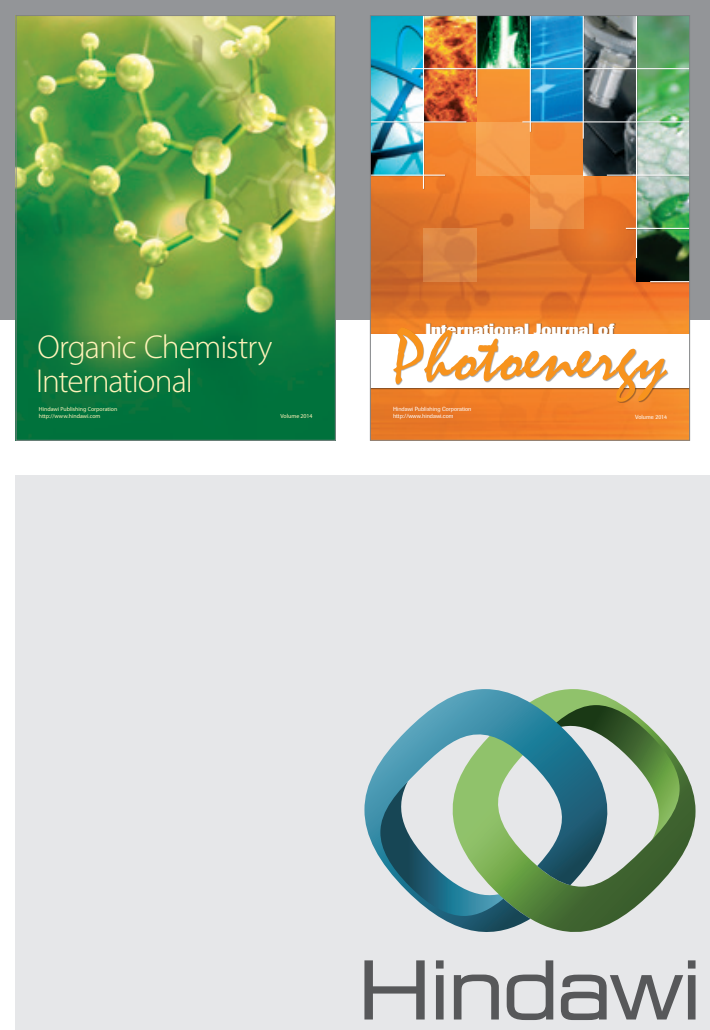

Submit your manuscripts at

http://www.hindawi.com
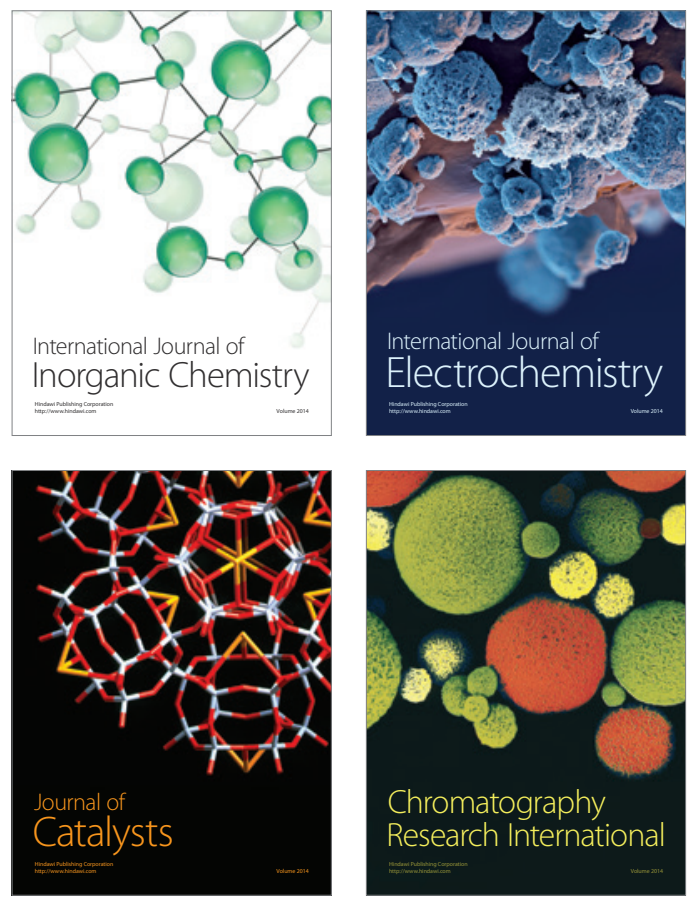
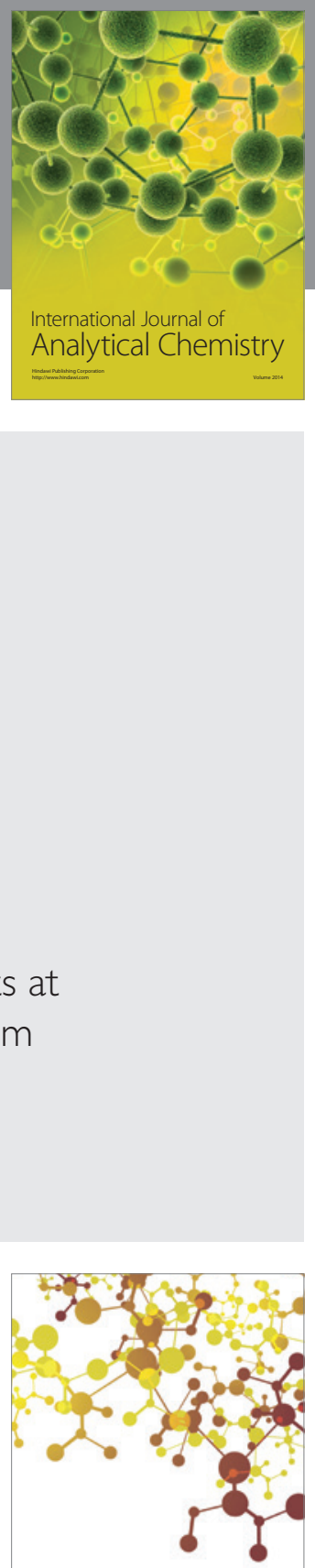

Journal of

Applied Chemistry
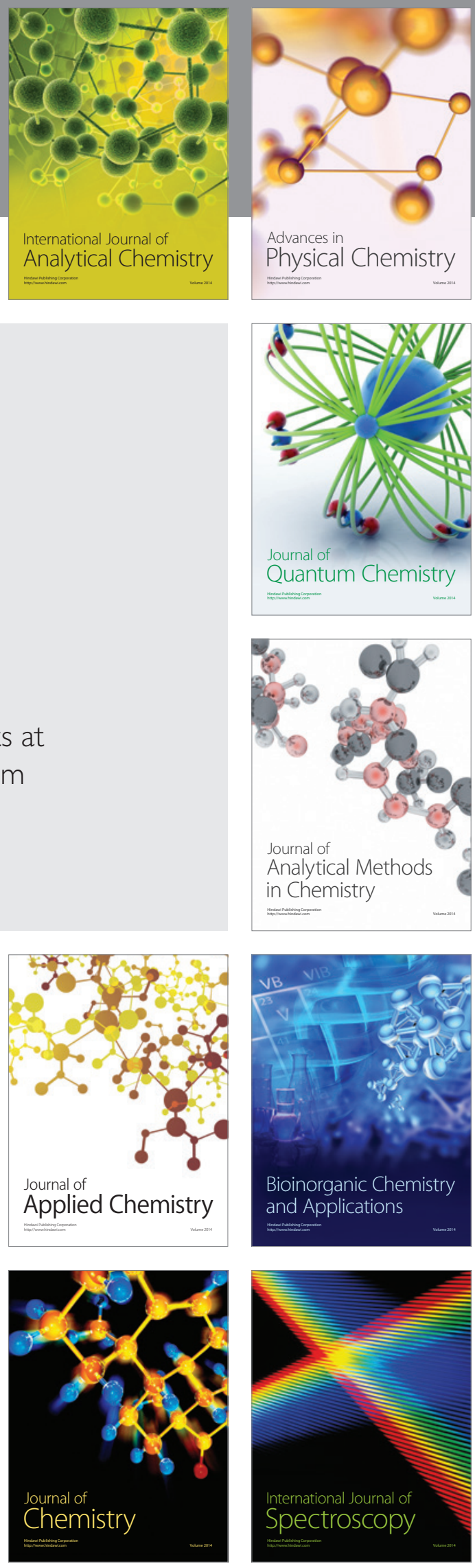